Vol. 1 No. 1 Januari 2022, e-ISSN : 2827-8070 | p-ISSN : 2827-8240

\title{
PENGELOLAAN KADALUARSA SEDIAAN FARMASI DENGAN TEKNIK TRAFFIC LIGHT DAN INDIGO DI RUMAHSAKIT PRATAMA BATU BUIL KABUPATEN MELAWI
}

\author{
${ }^{1}$ AGUNG ARIF PERKASA, ${ }^{2}$ ERSA TRI FITRIASARI \\ ${ }^{1}$ Rumah Sakit Pratama Batu Buil Melawi \\ ${ }^{2}$ Badan Pengembangan Sumberdaya Manusia Provinsi Kalimantan Barat \\ Email : ersa3.dhobithoh@gmail.com
}

\begin{abstract}
ABSTRAK
Mewujudkan sistem pemerintahan yang baik serta untuk mewujudkan tujuan suatu organisasi pemerintahan maupun mewujudkan good government. Selain itu juga kegiatan aktualisasi dilaksanakan dalam rangka mewujudkan prinsip pelayanan publik yang efektif dan efisien yaitu memberikan pelayanan kefarmasian khususnya mengelola kadaluarsa sediaan farmasi secara mudah dan murah, serta dilakukan dengan prosedur yang sederhana. Tujuan khusus dari penelitian ini untuk memudahkan dan mengoptimalkan petugas kefarmasian dalam mengelola obat dan mengawasi obat yang akan mendekati kadaluarsa, meningkatkan kualitas dan keamanan pelayanan kesehatan dengan mencegah pemberian sediaan farmasi yang kadaluarsa dengan melakukan pemberian stiker penandaan dan penggolongan berdasarkan jenis dan masa kadaluarsa. Hasil penelitian ini menunjukkan bahwa tersedianya kotak obat yang sesuai untuk penyimpanan sediaan farmasi dan tersusun, tersimpannya sediaan farmasi berdasarkan abjad dan jenis masing-masing dan dilakukan pemisahan sediaan farmasi sesuai bentuk dan jenisnya masing-masing, yang kemudian dilanjutkan dengan menyimpan dan menyusun sediaan tersebut kedalam kotak yang sudah dibuat sebelumnya berdasarkan abjad dan jenisnya. Pemasangan label nama serta traffic light dan melakukan teknik INDIGO (menandai dan menggolongkan) terhadap sediaan farmasi yaitu tersedianya label traffic light
\end{abstract}

Kata Kunci: Prosedur, Apoteker, Good Government

\section{ABSTRACT}

Realizing a good government system and to realize the goals of an organization as well as realizing good governance. In addition, actualization activities are carried out in order to realize effective and efficient public services, namely providing pharmaceutical services, especially managing the expiration of pharmaceutical preparations easily and cheaply, and carried out with simple procedures. The specific objectives of this study are to facilitate and optimize pharmaceutical officers in managing drugs and monitoring drugs that are approaching expiration, improving quality and health services by preventing the provision of expired pharmaceutical preparations by providing labeling and classifying the type and expiration date. The results of this study indicate that the availability of appropriate drug boxes for storage of preparations and collections, storage of preparations based on alphabetical order and each type, and separation of preparations according to their respective forms and types, which is then continued by storing and arranging these preparations into separate boxes. pre-made alphabetically and by type. Installing name labels and traffic lights and performing the INDIGO technique (marking and classifying) pharmaceutical preparations, namely the availability of traffic light labels

Keywords: Procedure, Pharmacist, Good Government

\section{PENDAHULUAN}

Salah satu wujud adanya pembangunan Nasional yang dilakukanoleh Pemerintah adalah melalui pembangunan kesehatan, diantaranyamelalui rumah sakit. Berdasarkan Permenkes Nomor 24 Tahun 2014 Tentang Rumah Sakit Kelas D Pratama dijelaskan bahwa Rumah Sakit Kelas D Pratama adalah rumah sakit umum yang hanya menyediakanpelayanan perawatan kelas 3 (tiga) untuk peningkatan akses bagi masyarakat dalam rangka menjamin upaya 
pelayanan kesehatan perorangan yang memberikan pelayanan rawat inap, rawat jalan, gawat darurat, serta pelayanan penunjang lainnya. Dalam upaya melakukan evaluasi terhadap standar pelayanan pasien, makaberdasarkan Undang-undang no. 44 tahun 2009 tentang Rumah Sakit mewajibkan rumah sakit menjalani akreditasi. Tujuan dari Akreditasi adalah menentukan apakah rumah sakit tersebut memenuhi standar yang dirancang untuk memperbaiki keselamatan dan mutu pelayanan.Salah satu komponen standar keselamatan pasien di rumah sakit yaitupelayanan kefarmasian. Berdasarkan Permenkes Nomor 72 Tahun 2016 Tentang Standar Pelayanan Kefarmasian di Rumah Sakit disebutkan bahwa Apoteker bertanggung jawab terhadap pengelolaanSediaan Farmasi, Alat Kesehatan, dan Bahan Medis Habis Pakai di Rumah Sakit, menjamin seluruh rangkaian kegiatan perbekalan Sediaan Farmasi sesuai dengan ketentuan yang berlaku serta memastikan kualitas, manfaat, dan keamanannya. Obat berperan sangat penting dalam pelayanan kesehatan. Penanganan dan pencegahan berbagai penyakit tidak dapat dilepaskan dari tindakan terapi dengan menggunakan obat atau farmakoterapi (Noviani \& Nurilawati, 2017). Pengelolaan obat adalah bagaimana cara untuk mengelola suatu sediaan obat agar dapat berjalan dengan baik dan

saling mengisi sehingga dapat tercapai sebuah tujuan pengelolaan obat yang efektif dan efisien agar obat yang diperlukan oleh pasien selalu tersedia setiap saat dibutuhkan dalam jumlah cukup serta mempunyai mutu yang terjamin (Nurniati, Lestari, \& Lisnawaty, 2016). Menurut Basha et al., (2015) tanggal kadaluarsa obat merupakan hari terakhir suatu perusahaan produksi obat menjamin keamanan obat secara penuh. Ketika produk obat berada pada masa kadalurarsa, dalam obat tersebut mengandung $90 \%$ senyawa aktif yang dapatmembahayakan tubuh manusia. Adapun penggunaan obat yang sudah kadaluarsa dapat menimbulkan efek samping yaitu hilangnya khasiat obat dan kandungan kimia yang terdapat didalamnya (Gul, A. et al., 2016). Pengelolaan obat yang tidak efisien menimbulkan dampak negatif secara medis maupun nonmedis. Hal tersebut mengakibatkan ketersediaan obat menjadi berkurang, obat menumpuk karena perencanaan yang tidak sesuai, serta biaya obat menjadi mahal karena penggunaan obat yang tidak rasional. Oleh karena itu diperlukan pengelolaan obat secara efektif, efisien dan rasional yang dilakukan secara berkesinambungan (Nurniati, Lestari, \& Lisnawaty, 2016).

Dari data yang diperoleh di Rumah Sakit Pratama Kabupaten Melawi didapatkan bahwa pada Tahun 2020 terdapat 30 jenis item sediaan farmasi yang mengalami kadaluarsa. Sedangkan rata-rata jumlah sisa stok sediaan farmasi per tahun yaitu terdapat 425 item sediaan farmasi. Perhitungan tingkat efektivitas pengelolaan sediaan farmasi dihitung dengan membandingkan jumlah item kadaluarsa dengan total jumlah sisa item obat per tahun dikali dengan 100\% (Pudjaningsih,1996). Maka persentase obat kadaluarsa di Rumah SakitPratama Batu Buil Melawi yaitu 7,05\%. Dimana total nilai sediaan farmasi kadaluarsa yaitu sebesar Rp. 9.225.000,00. Jika dibandingkan dengan standar yang ditetapkan Pudjaningsih (1996) persentase kadaluarsa obat pada suatu pelayanan kefarmasian adalah maksimal $0,2 \%$, dimana dapat dilihat bahwa terdapat ketidakefektifan dan efisiensi dalam pengelolaan sediaan farmasi yang ada dan berakibat pada keselamatan pasien maupun kerugian bagi rumah sakit itu sendiri. Oleh sebab itu mengingat perlunya penanganan dalam mengurangi dampak akibat sediaan yang mengalami kadaluarsa tersebut penulis menyampaikan gagasan bahwa diperlukan adanya suatu standar prosedur operasional dalam sistem pengelolaan sediaanfarmasi berdasarkan penandaan dan penggolongan masa kadaluarsa dari masing-masing item sediaan farmasi.

Berdasarkan penjelasan diatas adanya pengelolaan sediaan farmasi untuk pelayanan kesehatan kepada masyarakat dan pengelolaan sediaan farmasi belum dilaksanakan secara efektif dan efisien. Maka dilakukannya bagaimana pengelolaan kadaluarsa sediaan farmasidi Rumah Sakit Pratama BatuBuil Kabupaten Melawi. Hal ini bertujuan untuk meningkatkan kualitasmutu berdasarkan standar prosedur pelayanan kefarmasian di rumah sakit serta agar sediaan farmasi dapat lebih mudah diawasi melalui penandaan dan penggolongan kadaluarsa dari setiap item.

Gagasan untuk mengatasi persoalan yang ada untuk pencapaian kepuasan dan 
kepercayaan masyarakat terhadap organisasi pelayanan kesehatan, meminimalkan kerugian bagi masyarakat dan instansi karena sistem pengelolaan kesehatan khususnya pada unit pelayanan kefarmasianbelum berjalan secara efektif dan efisien. Peran Apoteker sebagai tenaga pelayanan kesehatan khususnya kefarmasian bertanggung jawab dalam pengoptimalan pengelolaan sediaan farmasi di fasilitas kesehatan dan solusi alternatif hambatan yang mungkin terjadi pada saat pengelolaan sediaan farmasi di fasilitas kesehatan

\section{METODE PENELITIAN}

Penelitian ini menggunakan pendekatan penelitian kualitatif, Nazir (2003:54) mengungkapkan bahwa pendekatan kualitatif adalah pendekatan dengan menggunakan data yang berupa kalimat tertulis atau lisan, peristiwa-peristiwa, pengetahuan, atau proyek studi yang bersifat deskriptif pada Rumah Sakit Pratama Kabupaten Melawi.

Berdasarkan Peraturan Menteri Kesehatan No. 24 Tahun 2014 disebutkan bahwa untuk memenuhi ketersediaan rumah sakit dalam rangka peningkatan akses pelayanan kesehatan kepada masyarakat terutama masyarakat miskin dan tidak mampu di daerah terpencil, perbatasan, kepulauan, dan tertinggal, serta daerah yang belumtersedia rumah sakit atau rumah sakit yang telah ada sulit dijangkau akibat kondisi geografis, perlu dibentuk Rumah Sakit Kelas D Pratama. Peraturan Menteri Pendayagunaan Aparatur Negara dan Reformasi Birokrasi Nomor 13 Tahun 2021 Tentang Jabatan Fungsional Apoteker disebutkan mengenai tugas Jabatan Fungsional Apoteker yaitu melaksanakan Praktik Kefarmasian yang meliputi penyusunan rencana Praktik Kefarmasian, pengelolaan Sediaan Farmasi, Alat Kesehatan, dan BMHP, pelayanan farmasi klinik, sterilisasi sentral, pelayanan farmasi khusus, serta penerapan kajian farmakoekonomi dan uji klinik.

\section{HASIL DAN PEMBAHASAN}

Akuntabilitas pelayanan publik berarti pertanggungjawaban pegawai pemerintah terhadap publik yang menjadi konsumen pelayanannya. Hal ini terkait dengan pemikiran/konsep masyarakat yang demokratis, dimana amanat yang diberikan oleh masyarakat kepada seseorang/sekelompok untuk mengatur kehidupan bermasyarakat, oleh seseorang/sekelompok orang tersebut harus mempertanggungjawabkannya kepada orang orang yang memberikan kepercayaan Transparansi/keterbukaan Choirul Saleh, (2012). Pelaksanaan pelayanan publik dengan berorientasi pada kualitas hasil. Adapun nilai - nilai komitmen mutu antara lain adalah mengedepankan komitmen terhadap kepuasan dan memberikan layanan yang menyentuh hati, untuk menjaga dan memelihara kualitas pelayanan.

Hasil wawancara mendalam mengidentifikasi proses pengelolaan sediaan farmasi, alat kesehatan dan BMHP menjelang kadaluarsa di Rumah Sakit Pratama Batu Buil Kabupaten Melawi bahwa pengelolaan kadaluarsa sediaan farmasi harus dilakukan sesuai dengan prosedur yang sudah dibuat dan perlu adanya penyesuaian melalui berbagai referensi dan data pendukung terkait standar prosedur yang sudah ada. Berdasarkan pengamatanlingkungan di pelayanan kefarmasian belum ada suatu prosedur dalam mengelola sediaan farmasi yang akan kadaluarsa dilihat dari banyaknyasediaan farmasi yang menumpuk pada gudang dan penyimpanan dan penataan yang belum optimal serta berdasarkan data yang dihimpun diketahui bahwa jumlah sediaan farmasi yang mengalami kadaluarsa pada tahun 2020 sebanyak 30 jenis item obat dengan penggunaan sediaan farmasi rata-rata sebanyak 60 jenis sediaan dari 210 resep yang keluar dalam periode satu bulan. Selain itu jumlah rata-rata sisa stok obatyang ada di gudang pada tahun 2020 sebanyak 425 item sediaan. Dari data tersebut dapat dihitung tingkat efektivitas dan efisiensi dalam pengelolaan sediaan farmasi dengan membandingkan jumlah obat kadaluarsa dan jumlah sisa stok rata-rata yang ada selama satu tahun menurut pedoman dari Pudjaningsih (1996) dari data tersebut diperolehangka 7,05\%. Hal ini menunjukkan perlu adanya perhatian terkait pengelolaan kadaluarsa sediaan farmasi dikarenakan berdasarkanpedoman maksimal nilai obat kadaluarsa dalam satu periode yaitu $0,2 \%$.

Pengelolaan Kadaluarsa Sediaan Farmasi di Rumah Sakit Pratama Batu Buil Kabupaten 
Melawi. Pertimbangan dari penentuan aspek isu aktual ini adalah untuk mempermudah adanya pengelolaan sediaan farmasi yang efektif, efisien serta aman.Hal ini sesuai dengan isi Permenkes Nomor 72 Tahun 2016 TentangStandar Pelayanan Kefarmasian di Rumah Sakit dan Undangundang nomor 44 Tahun 2009 tentang Rumah sakit. Pelayanan medis, serta bisa menimbulkan efek yang berbahaya apabila pasien menggunakan sediaan farmasi yang mengalami kadaluarsa maka pentingnya mengurangi keefektifan dan efisiensi dalam pengelolaan sediaan farmasi yang akan menurunkan tingkat kepuasan publik terhadap kualitas mutu pelayanan yang diberikanoleh Rumah Sakit.

Pendataan semua sediaan farmasi bertujuan untuk mewujudkan visi misi organisasi dalam rangka untuk bisa mewujudkan masyarakat yang mandiri untuk hidup sehat dengan memberikan pelayanan yaitu tersedianya tabel data sediaan farmasi berdasarkan 3 jenis masa kadaluarsa diikuti tersedianya data stok obat secara jelas pada kartu stok disertai masa kadaluarsanya. Perekapan seluruh sediaan farmasi yang ada di gudang dan ruang penyerahan obat dengan mencatat waktu kadaluarsa dan sisa stok sediaan. Selanjutnya dilakukan pembagian kedalam tiga jenis waktu kadaluarsa sediaan dan kemudian dilakukan pencetakan tabel tersebut dan ditempelkan pada bagian unit terkait seperti pada apotek poli umum, poli gigi, kebidanan dan laboratorium. Setelah itu dilakukan pencocokkan data dengan kartu stok yang ada.

Tersedianya kotak obat yang sesuai untuk penyimpanan sediaan farmasi dan tersusun, tersimpannya sediaan farmasi berdasarkan abjad dan jenis masing-masing dan dilakukan pemisahan sediaan farmasi sesuai bentuk dan jenisnya masing-masing, yang kemudian dilanjutkan dengan menyimpan dan menyusun sediaan tersebut kedalam kotak yang sudah dibuat sebelumnya berdasarkan abjad dan jenisnya. Pemasangan label nama serta traffic light dan melakukan teknik INDIGO (menandai dan menggolongkan) terhadap sediaan farmasi yaitu tersedianya label traffic light, tersedianya label nama obat. Pada kegiatan ini diawali dengan membuat label nama obat yang akan digunakan pada kotak penyimpanan. Dilanjutkan dengan membuat label penandaan dengan tiga golongan warna yaitu merah untuk sediaan dengan kadaluarsa antara 0-6 bulan, kuning untuk sediaan dengan kadaluarsa antara 7-12 bulan serta hijau untuk sediaan dengan kadaluarsa lebih dari 12 bulan. Selanjutnya dilakukan pencetakan label nama dan label traffic light tersebut dan kemudian dilakukan penandaan pada setiap kotak penyimpanan pada ruang penyerahan obat dan gudang farmasi sesuai dengan jenis kadaluarsa masing-masing sediaan.

Hasil pengukuran kegiatan dilaksanakan, guna memperoleh masukan dan saran terkait pelaksanaan kegiatan sehingga menjadi lebih baik lagi. Kegiatan ini diawali dengan menyampaikan hasil capaian, kekurangan dan hambatan selama kegiatan pengelolaan kadaluarsa sediaan farmasi di rumah sakit sebagai bentuk perbaikan terus- menerus dan tanggung jawab terhadap kegiatan yang sudah berjalan. Selanjutnya merencanakan perbaikan terhadap kegiatan yang telah dilakukan agar memperoleh hasil yang lebih baik. Kemudian saya melakukan koordinasi dengan atasan terkait teknis perbaikan kegiatan pengelolaan kadaluarsa sediaan farmasi di rumah sakit yang dikerjakan

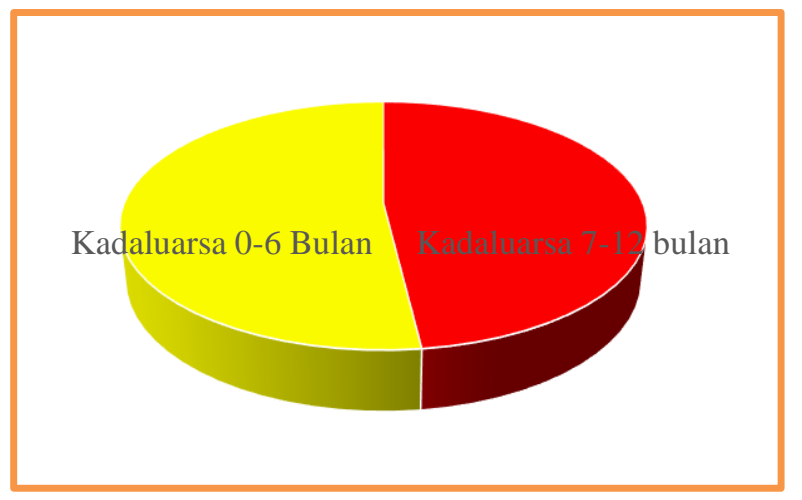

Gambar 1. Diagram Kadaluarsa Sediaan Farmasi 
Dari diagram diatas dapat disimpulkan bahwa sediaan farmasi yang mengalami kadaluarsa dalam waktu 0-6 bulan berjumlah 25 item sediaan sedangkan sediaan farmasi yang mengalami kadaluarsa dalam 6-12 bulan berjumlah 27 item sediaan. Jumlah tersebut diambil dari hasil pendataan sediaan farmasi pada bulan oktober 2021

\begin{tabular}{|c|c|c|c|c|c|c|}
\hline \multirow[b]{2}{*}{ No. } & \multicolumn{6}{|c|}{$\begin{array}{l}\text { FORMULIR PEMANTAUAN OBAT KADALUARSA } \\
\text { TAHUN } 2021\end{array}$} \\
\hline & Bulan & $\begin{array}{l}\text { Tanggal } \\
\text { Minggu I }\end{array}$ & $\begin{array}{l}\text { Tanggaal } \\
\text { Minggu II }\end{array}$ & $\begin{array}{l}\text { Tanggal } \\
\text { Minggu III }\end{array}$ & $\begin{array}{l}\text { Tanggal } \\
\text { Minggu IV }\end{array}$ & $\begin{array}{c}\text { Paraf } \\
\text { Petugas }\end{array}$ \\
\hline 1. & Januari & & & & & $>$ \\
\hline 2. & Februari & & & & & 7 \\
\hline 3. & Maret & & & & 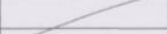 & \\
\hline 4. & April & . & & & 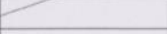 & \\
\hline 5. & Mei & & & & & \\
\hline 6. & Juni & & & & & \\
\hline 7. & Juli & & 1 & & & \\
\hline 8. & Agustus & & & & & \\
\hline 9. & September & $\angle$ & 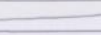 & & & \\
\hline 10. & Oktober & & & & 260 ktober 2021 & 78 \\
\hline 11. & November & & & & & \\
\hline 12. & Desember & & & & & \\
\hline
\end{tabular}

Gambar 2. Formulir Pemantauan Obat Kadaluarsa

Tabel 1. Perbedaan Kegiatan Sebelum dan Sesudah Aktualisasi

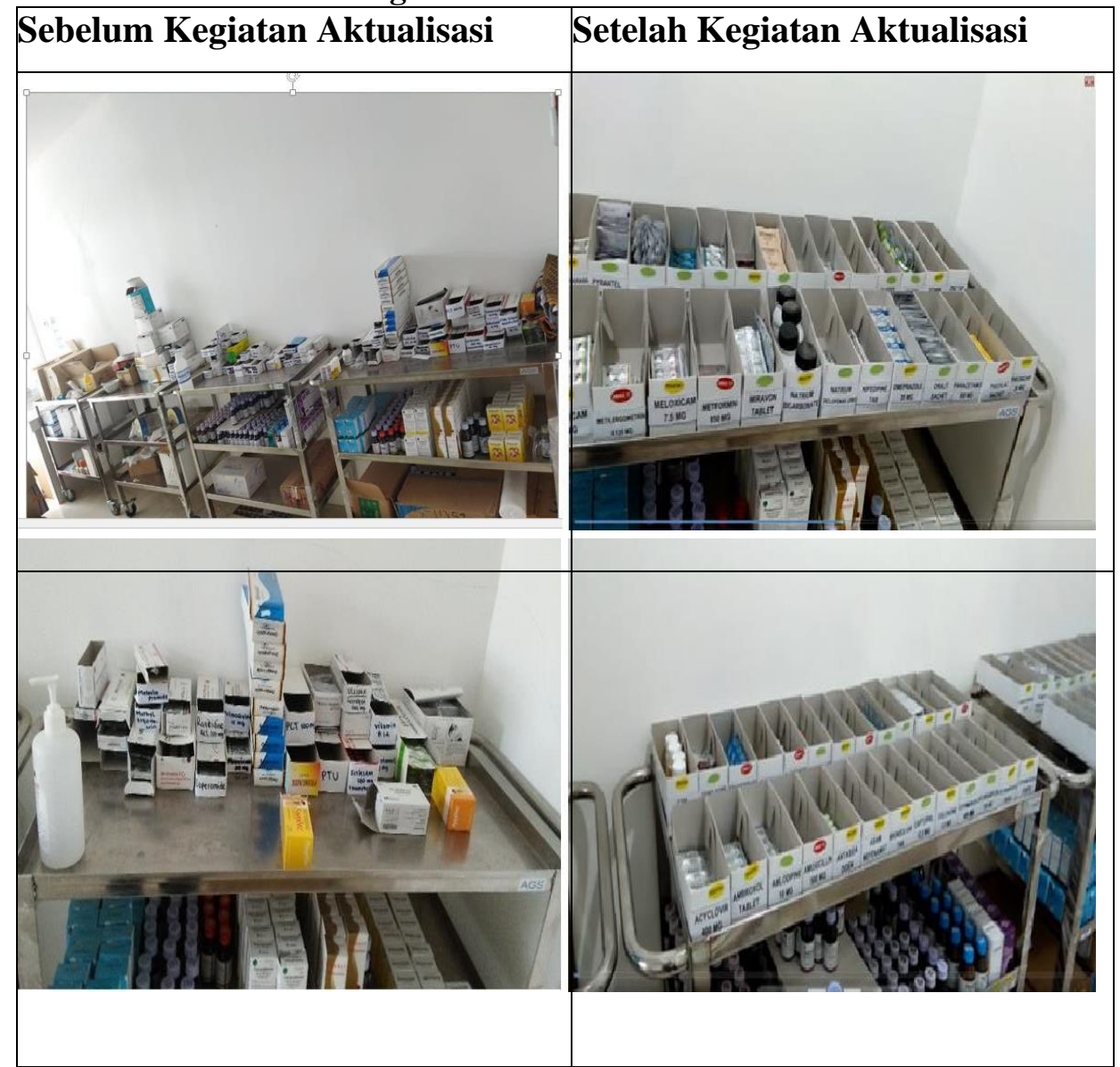




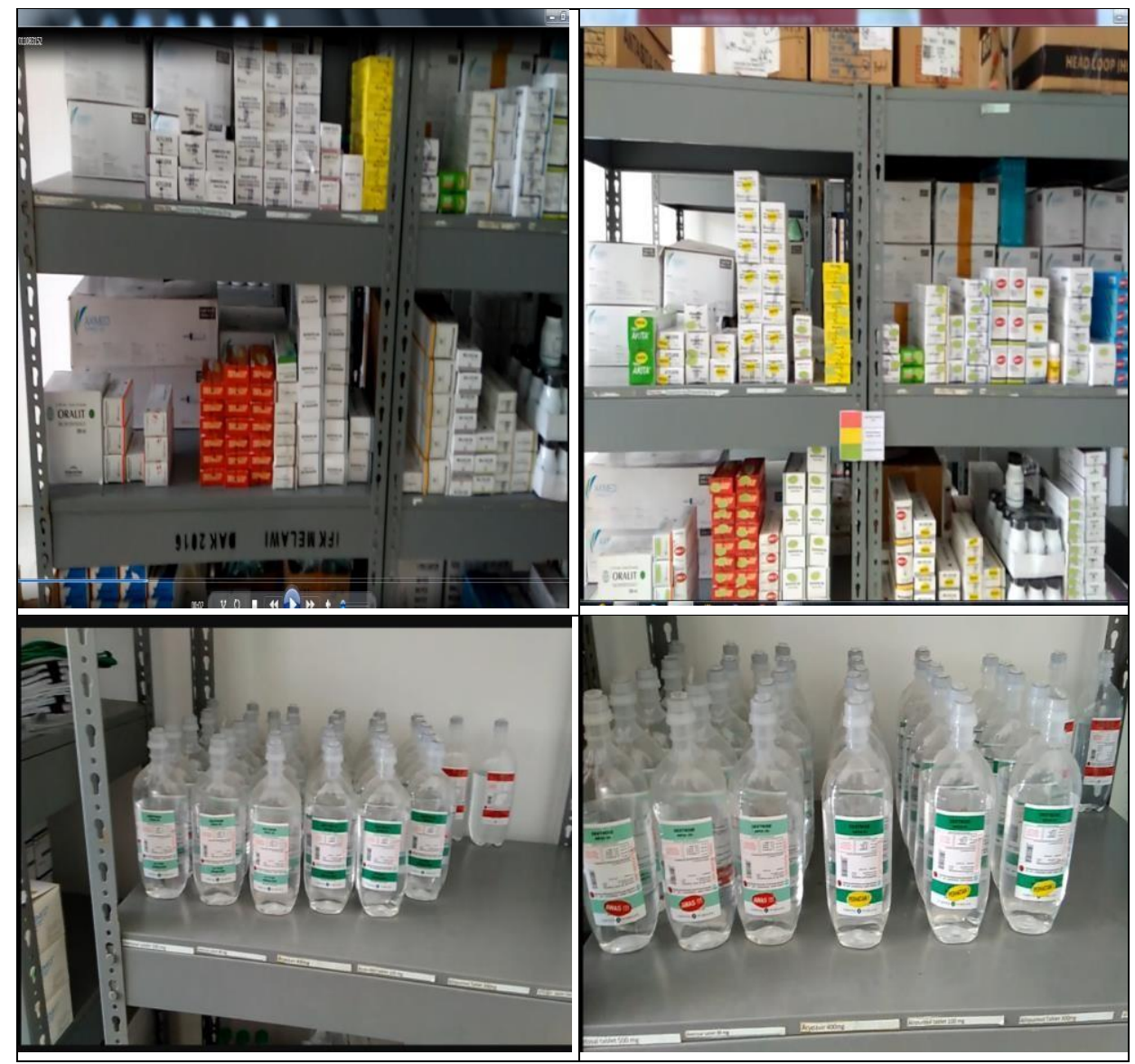

Dalam tabel tersebut dapat kita lihat bahwa kegiatan setelah kegiatan aktualisasi sediaan obat bertambah dan komponen dari obat obat diatas menjadi lengkap lalu untuk ketataan nya menjadi lebih teratur. Hal ini membuktikan bahwa traffic light yang di gunakan menjadi lebih baik daripada sebelum menggunakan teknik tersebut.

\section{KESIMPULAN}

Pengelolaan Kadaluarsa Sediaan Farmasi dengan Teknik Trrafficlight dan INDIGO (Menandai dan Menggolongkan) di Rumah Sakit Pratama Batu Buil Kabupaten Melawi" tersebut dapat diambil kesimpulan bahwa kegiatan aktualisasi dalam rangka pengelolaan kadaluarsa sediaan farmasi penting dilakukan sebab berdasarkan hasil aktualisasi diperoleh bahwa terdapat perbedaan yang signifikan dari sisi penyimpanan dan penggolongan sediaan farmasi dalam membantu para petugas kefarmasian agar lebih mudah dalam melakukan pengawasan kadaluarsa sediaan farmasi sehingga bisa meningkatkan kualitas dan kemanan bagi pelayanan kesehatan khusunya dalampelayanan kefarmasian.

Berdasarkan permasalahan yang ada di lapangan tersebut telah dilakukan kegiatan aktualisasi berupa peningkatan dalam mengoptimalisasi pengelolaan kadaluarsa sediaan farmasi melalui penandaan pada 25 jenis sediaan farmasi yang akan kadaluarsa dalam waktu kurang dari 6 bulan. Dan juga telah dilakukanpembuatan kotak sediaan penyimpanan sediaan farmasi agar bisa memaksimalkan proses pengawasan obat yang akan kadaluarsa. Kegiatan ini juga sudah dilakukan secara berkolaborasi dengan unit pelayanan terkait sehingga akan memberikan hasil yang optimal.

\section{DAFTAR PUSTAKA}

Basha, Babu, K.R., Madhu, Kumar, Y, \& Gopinath. (2015). Recycling of Drug From Expired

Drug Productss Comprehensive Review. Journal of Global Trends in Pharmaceutical Sciences, Vol. 6(2): 2596 - 2599.

Choirul Saleh, 2012, Jurnal Ilmiah Administrasi Publik Vol 13, No 1, E-Government Sebagai 
Inovasi Pelayanan Publik Di Indonesia Antara Harapan Dan Kenyataan

Gul, A., Nazish, S., Sabir, S., Nazish, H. \& Masood, T. 2016. Expired Drugs - Awareness and Pracrices of Outdoor Patiens. Journal of Rawalpindi Medical College Students Supplement 20(S-1):45-48.

Lembaga Administrasi Negara Republik Indonesia, 2015. Akuntabilitas PNS, ModulPelatihan Dasar, Jakarta: LAN RI.

Noviani, N. Nurilawati, V. 2017. Bahan Ajar Keperawatan Gigi Farmakologi.

Kementrian Kesehatan Republik Indonesia

Nurniati L, Lestari H, Lisnawaty. Studi tentang Pengelolaan Obat di Puskesmas Buranga Kabupaten Wakatobi tahun 2016. Fakultas kesehatan Masyarakat Universitas Halu Oloo. 2016

Peraturan Menteri Kesehatan Republik Indonesia. Nomor 24 tahun 2014. tentang

Rumah Sakit Kelas D Pratama.

Permenkes, 2016. Peraturan Menteri Kesehatan Republik Indonesia Nomor 72 Tahun 2016

Tentang Standar Pelayanan kefarmasian di Rumah sakit.Jakarta: Kementrian Kesehatan Republik Indonesia

Peraturan Menteri Pendayagunaan Aparatur Negara dan Reformasi Birokrasi Nomor 13 Tahun 2021 Tentang Jabatan Fungsional Apoteker

Permenkes Nomor 377/MENKES/PER/V/2009 Tentang Petunjuk Teknis Jabatan Fungsional Apoteker Dan Angka Kreditnya

Peraturan Menteri Pendayagunaan Aparatur Negara dan Reformasi Birokrasi Nomor PER/07/M.PAN/4/2008 Tahun 2008. Jabatan Fungsional Apoteker dan Angka Kreditnya

Regester, Michael, Judy Larkin. 2003. Risk Issues and Crisis Management in PublicRelations. New Delhi: Crest Publishing House

Sinambela, Lijan Poltak, dkk. 2010. Reformasi Pelayanan Publik. Jakarta: BumiAksara. Undang-Undang RI Nomor 44 Tahun 2009 tentang Rumah Sakit.Jakarta:2009 